Research Article

\title{
In Vitro and In Vivo Antifungal Activity of Clove (Eugenia caryophyllata) and Pepper (Piper nigrum L.) Essential Oils and Functional Extracts Against Fusarium oxysporum and Aspergillus niger in Tomato (Solanum lycopersicum L.)
}

\author{
Laila Muñoz Castellanos, ${ }^{1}$ Nubia Amaya Olivas $\mathbb{D}^{\mathbb{C}},{ }^{1}$ Juan Ayala-Soto, ${ }^{1}$ \\ Carmen Miriam De La O Contreras, ${ }^{1}$ Miriam Zermeño Ortega, ${ }^{1}$ Fabiola Sandoval Salas, ${ }^{2}$ \\ and Leon Hernández-Ochoa $\mathbb{i D}^{1}$ \\ ${ }^{1}$ Universidad Autónoma de Chihuahua, Facultad de Ciencias Químicas. Circuito Universitario, Campus Universitario No. \#2, \\ Chihuahua, Chihuahua C. P. 31125, Mexico \\ ${ }^{2}$ Tecnológico Nacional de México, Instituto Tecnológico Superior de Perote, Carretera Federal México-Perote 140, Centro, \\ 91270 Perote, Veracruz, Mexico
}

Correspondence should be addressed to Leon Hernández-Ochoa; lhernandez@uach.mx

Received 23 January 2020; Revised 4 March 2020; Accepted 10 March 2020; Published 1 May 2020

Academic Editor: Simona Nardoni

Copyright (C) 2020 Laila Muñoz Castellanos et al. This is an open access article distributed under the Creative Commons Attribution License, which permits unrestricted use, distribution, and reproduction in any medium, provided the original work is properly cited.

In this study, hydrodistillation was used to obtain essential oils (EOs) from pepper (Piper nigrum L.) and clove (Eugenia caryophyllata) and co-hydrodistillation (addition of fatty acid ethyl esters as extraction co-solvents) was used to obtain functional extracts (FEs). Antifungal activity of EOs and FEs was evaluated by determination of minimum inhibitory concentration (MIC) against Fusarium oxysporum and Aspergillus niger. The results showed that pepper (Piper nigrum) and clove (Eugenia caryophyllata) essential oils and their functional extracts are effective in vitro at concentrations from 400 to 500 ppm after 10 days of culturing. The essential oils and functional extracts were used on tomato fruit samples at three different concentrations: 350 , 400, and $450 \mathrm{ppm}^{5}$. Clove essential oil reduced the growth of Aspergillus niger from 50\% to $70 \%$ and Fusarium oxysporum to $40 \%$. The functional extracts (FEs) of clove and pepper, mixed with ethyl decanoate $\left(\mathrm{FEs}-\mathrm{C}_{10}\right)$, were the best combination for protecting the tomato fruit in vivo against both phytopathogenic fungi. Gas chromatography-mass spectrometry (GC-MS) was used to identify eugenol as the principal compound in clove oil and limonene, sabinene, and $\beta$-caryophyllene in pepper oil.

\section{Introduction}

Tomato (Solanum lycopersicum L.) is the second most consumed vegetable worldwide [1]. Tomatoes are an important source of lycopene, carotenes, ascorbic acid, and potassium [2]. However, this crop is affected by several diseases caused by a wide number of pathogens, resulting in reduction in fruit yield and quality, coupled with large economic losses $[1,3]$. Vascular wilt caused by Fusarium oxysporum is a serious soil disease of tomato [4]. The pathogen attacks susceptible plants by root infection and then clogs the vascular system with mycelia or spores causing vascular and leaf discoloration, often leading to the death of the plant $[5,6]$. Likewise, Aspergillus niger is one of the major pathogenic fungi in tomato fruit, such as $\mathrm{Hel}$ minthosporium solani and Penicillium digitatum [7] One of the most prominent alternatives to conventional agriculture is the use of plant products which have been shown to control many phytopathogens previously reported [7, 8]. Essential oils are one of these plant products with great potential for controlling plant diseases, since they present antibacterial, antiviral, antifungal, and insecticide activity 
$[8,9]$. The antimicrobial activity of essential oils is directly correlated with the presence of their bioactive volatile components such as terpene compound (mono-, sesqui-, and diterpene), alcohols, acids, esters, epoxides, aldehydes, ketones, amines, ethers and phenols $[9,10]$. The antifungal action of essential oils may be attributed to their capability to disrupt cell wall and cell membrane and coagulate the cytoplasm, and hence they damage cellular organelles and allow escape of macromolecules [11-13]. The lipophilic nature of EOs allow them to pass through the cell wall and damage the cytoplasmic membrane while disrupting various layers of polysaccharide, fatty acids, and phospholipids, eventually making them permeable [14-16]. Recently, antifungal mechanism of action of EOs has been reported by measuring the ergosterol content of plasma membrane of test fungi [17]. Ergosterol is a major sterol component of the fungal cell membrane responsible for maintaining the cell function and integrity. Ergosterol is found almost exclusively in fungi and therefore used extensively as an indicator of fungal biomass [18]. The most common method of essential oil extraction is by hydrodistillation, although petroleumderived solvents are also used to purify plant-derived compounds. However, the latter method can be dangerous because of the use of explosive and toxic solvents. An option would be the use of alternative solvents, also known as green solvents because they are not derived from petroleum products; therefore, they are not as detrimental to the environment. Among those alternative solvents, fatty acid ethyl esters extracted from plants are becoming an important option because of their amphipathic property and biodegradability, and they are also nontoxic and nonirritable [19]. The aim of the present work was to evaluate the antifungal effects of essential oils and functional extracts from clove (Eugenia caryophyllata) and pepper (Piper nigrum L.) for reducing the severity of Fusarium oxysporum and Aspergillus niger wilt in tomato (Solanum lycopersicum L.) using a series of in vitro and in vivo evaluations.

\section{Materials and Methods}

2.1. Raw Material. The vegetal material used in this study was Clove (Eugenia caryophyllata) and pepper (Piper nigrum L.) provided by Comercial Cordona from Chihuahua, Mexico. The fatty acid ethyl esters used as co-solvent in the co-hydrodistillation process were ethyl decanoate $\left(\mathrm{C}_{10}\right.$, CAS number 110-38-3, 99\%, Sigma-Aldrich), ethyl undecanoate $\left(\mathrm{C}_{11}\right.$, CAS number 627-90-7, 99\%, Sigma-Aldrich), ethyl dodecanoate $\left(\mathrm{C}_{12}\right.$, CAS number 106-33-2, 99\%, SigmaAldrich), and ethyl tetradecanoate ( $\mathrm{C}_{14}$, CAS number 12406-1, 99\%, Sigma-Aldrich). Isolates of Fusarium oxysporum and Aspergillus niger were used in this study. The strains are part of the Fungi Culture Collection of the School of Chemical Sciences.

2.2. Extraction of Essential Oils (EOs) and Functional Extracts (FEs). Clove (Eugenia caryophyllata) and pepper (Piper nigrum L.) were individually subjected to a hydrodistillation process using the modified Schilcher device. In hydrodistillation, the plants were immersed in water, where the system was heated to the boiling point of water. For cohydrodistillation, fatty acid ethyl esters were added as cosolvent, and the homogeneous mixture was called functional extracts (FEs). The fatty acid ethyl esters used in this study were ethyl decanoate $\left(\mathrm{C}_{10}\right.$, CAS number 110-38-3), ethyl undecanoate $\left(C_{11}\right.$, CAS number 627-90-7), ethyl dodecanoate $\left(\mathrm{C}_{12}\right.$, CAS number 106-33-2), and ethyl tetradecanoate $\mathrm{E}_{14}$, CAS number 124-06-(1). For this process, $200 \mathrm{~g}$ of vegetal material, $4 \mathrm{~L}$ of water, and $20 \mathrm{~mL}$ of ethyl ester were used for the clove and pepper [20].

\subsection{Analysis of Essential Oils and Functional Extracts.} The essential oil and functional extracts were collected and diluted with hexane in a volumetric flask; the solutions obtained were analyzed by GC-MS (gas chromatographymass spectrometry). The analysis of essential oils and functional extracts was conducted using a gas chromatographic system (Perkin-Elmer Instrument, Auto system XL, USA) equipped with a DB-5 column (5\% phenyl methylpolysiloxane, $20 \mathrm{~m} \times 0.1 \mathrm{~mm}$ i.d. and $0.4 \mu \mathrm{m}$ film thickness) and a mass spectrometer (Perkin-Elmer instruments TurboMass Gold) as detector.. The carrier gas was helium, at a flow rate of $1 \mathrm{ml} / \mathrm{min}$. For the GC-FID analysis, the temperature was increased from $60^{\circ} \mathrm{C}$ to $180^{\circ} \mathrm{C}$ at $1^{\circ} \mathrm{C} / \mathrm{min}$. The injector and detector temperature were set at $180^{\circ} \mathrm{C}$.

\subsubsection{Effect of Essential Oils on Radial Growth: Minimum} Inhibitory Concentration (MIC). In order to prove the efficacy of the bioactive compounds of EOs and FEs against $F$. oxysporum and $A$. niger, the final concentrations of each used in potato dextrose agar (PDA) were 100, 200, 300, 400, and $500 \mathrm{ppm}$. The controls were prepared with agar and ethanol and pure ethyl decanoate, ethyl undecanoate, ethyl dodecanoate, and ethyl myristate at a $100 \mathrm{ppm}$ concentration. Treatments were randomly arranged with four replications. To promote infection, treated tomato fruits were kept in a humid chamber at $30^{\circ} \mathrm{C}$ in darkness. The diameter of the radial growth caused by Fusarium oxysporum and Aspergillus niger was measured 10 days after inoculation.

2.4. Inoculum Production. The inoculum was prepared by culturing Fusarium oxysporum and Aspergillus niger in darkness at $25^{\circ} \mathrm{C}$ on PDA for 14 days in Petri dishes. The conidial suspension was prepared with sterile distilled water and Tween 80 and quantified by a Neubauer chamber to adjust at $1.5 \times 10^{5}$ conidia $/ \mathrm{mL}$.

2.5. In Vivo Protection Assay. For the in vivo assays, three concentrations were tested: 350,400 , and $450 \mathrm{ppm}$, but only with the clove essential oil (EO), as well as different clove extracts (FEs) with different esters.

Fresh and healthy round tomatoes (Solanum lycopersicum L.) were disinfected with $90 \%$ ethanol and rinsed with sterile distilled water. A $6 \mathrm{~mm}$ diameter hole was made on the skin of the tomato fruit using a sterile cork-borer, and then $100 \mu \mathrm{L}$ of the spore suspensions $\left(1.5 \times 10^{5}\right.$ conidia/mL) 
was added on the area; then the epidermis was put back and sealed with sterile petroleum jelly (only on the edges of the cut to avoid fruit oxidation). After fungal inoculation, tomato fruits were sprayed with EO and FEs at 350, 400, and $450 \mathrm{ppm}$. Control tomato fruits were sprayed with sterile distilled water-ethanol (2\%). Treatments were randomly arranged with three replications. To promote infection, treated tomato fruits were kept in a humid chamber at $28^{\circ} \mathrm{C}$ in darkness. The diameter of the rotting area caused by Fusarium oxysporum and Aspergillus niger was measured every day during fifteen days' postinoculation.

\section{Results and Discussion}

3.1. Chemical Composition of Plant Essential Oils and Functional Extracts. The results obtained from the extraction process show that when comparing the extraction yields obtained by the hydrodistillation and co-hydrodistillation methods for each spice, the yield for clove is higher than pepper. This behavior is observed likewise in the percentages obtained from each of the functional extracts. This can be explained generally because in the plant, essential oils are stored or located in glands, conduits, sacs, or glandular hairs or in reservoirs in the plant; therefore, the exposure of these reservoirs to the action of the distillation vapor allows the vapor to soften or break the walls of the oily glands, releasing the oils, favoring extraction yield [11]. Results obtained from the chromatographic analysis are detailed in Table 1, which shows the principal components of clove and pepper essential oils and functional extracts. In the clove extracts, Eugenol was identified as majority component, which is also found in majority proportion (70-85\%). Other determined components are the esters ethyl decanoate, ethyl undecanoate, ethyl dodecanoate, and ethyl tetradecanoate, whose percentage corresponds to $4-17 \%$ of the relative composition; these were added in the co-hydrodistillation process. In addition to these components, there were identified eugenyl acetate $(15 \%)$ and $\beta$-caryophyllene. These results match Hernández-Ochoa et al. [21] and Jirovetz et al. [22], who report that clove essential oil may contain up to $90 \%$ eugenol, in addition to eugenyl acetate ( $2 \%$ to $7 \%$ ), as well as the presence of caryophyllene. In the case of the pepper essential oil, it was determined the presence of limonene $(18.8 \%)$, sabinene $(16.5 \%), \beta$-caryophyllene $(15.6 \%)$, and $\beta$-pinene (10\%) as majority compounds; in addition to this, another group of compounds was determined at a lower proportion (Table 2 ). These results are consistent with the reports of several authors [23, 24], where these are identified as majority compounds; however, they mention the presence of a total of 22 compounds in some cases, which differ from the total 8 compounds that were determined at a lower proportion. This difference in the chemical composition may be attributed to the origin of the fruit, as well as to different growing and/or simple conservation conditions.

3.2. Fungi Identification. Fusarium oxysporum showed an exponential growth, as well as a flat cottony morphology that tended to extend, developing a white aerial mycelium as observed in Figure 1. It can be observed the production of a mycelium of characteristic white color which turned into pink salmon; it was also observed that white colonies spread pigmentation to the medium. After 72 hours, the growth of the colonies was $2 \mathrm{~cm}$. Microscopically were observed abundant microconidia, which are generated in simple phialides emerging laterally; they present a slightly curved oval-elipsoid form, and they lack septa. Macroconidia also present a pedicelled base; some have three to five septa; three-septate spores were more common. These results match the research of Nelson [25], where it is mentioned the presence of three kinds of spores: macroconidia, elongated spores with 3 to 5 septa, with a shape typical of the genus; microconidia, oval shaped and abundant; and chlamydospores that allow distinguishing $F$. oxysporum from $F$. moniliforme [10]. In the case of Aspergillus niger, it was observed that colonies, initially white, grew fast; however, the mycelial surface was covered with black spots that represent Aspergillus heads (Figure 1), measuring up to $1 \mathrm{~mm}$ in diameter, charged with black spores that turned into a pulverulent culture, forming a dense felt of erect conidiophores. The observed microscopic characteristics showed that it presents a single conidiophore originated in a partitioned hypha; this aerial conidiophore ends in an enlarged vesicle containing double or single projections; these are phialides, out of which extends a single, sometimes long chain of small round conidia [26].

\subsection{Evaluation of In Vitro Antifungal Activity of EOs and FEs}

3.3.1. Antifungal Activity of Clove (Eugenia caryophyllata). The extracts' in vitro fungicide activity was evaluated by determining the capacity of inhibition of mycelial growth of each of the species under study. The clove essential oil presented the greater biological activity of all the treatments used, achieving a total inhibition of the growth of the species evaluated. In the treatment of clove essential oil against Fusarium oxysporum, the biological activity was proportional to the increase in concentration, as shown in Table 3. It is observed a mycelial growth of $5.6 \mathrm{~cm}$ at a concentration of $100 \mathrm{ppm}$, with mycelial growth significantly reduced to $400 \mathrm{ppm}(0.44 \mathrm{~cm})$. At $500 \mathrm{ppm}$, it is observed a total inhibition of $F$. oxysporum, with the essential oil showing greater inhibition compared to the growth of the corresponding control sample at $7.72 \mathrm{~cm}$. The same behavior was observed against the species Aspergillus niger; the results obtained show a mycelial growth of 6.12 at a concentration of $100 \mathrm{ppm}$, which is modified at $200 \mathrm{ppm}$ obtaining a value of $1.98 \mathrm{~cm}$; total inhibition is observed at $400 \mathrm{ppm}$ and above. In the case of clove functional extracts against mycelial growth of F. oxysporum (Table 3), the same behavior of the essential oil was observed, that is, an average growth of $6.5 \mathrm{~cm}$ was observed at a concentration of $100 \mathrm{ppm}$. The extracts of clove- $\mathrm{C}_{10}$ and clove- $\mathrm{C}_{12}$ showed a mycelial growth for $A$. niger of $6.23 \mathrm{~cm}$ and $6.38 \mathrm{~cm}$, respectively, at $100 \mathrm{ppm}$, very similar to the growth obtained at the same concentration of the clove essential oil. In the case of the extracts of clove $\mathrm{C}_{11}$ and $\mathrm{C}_{14}$ it was observed a mycelial 
TABLE 1: Main compounds determined in clove (Eugenia caryophyllata) essential oil.

\begin{tabular}{lcccc}
\hline Compound & Retention time & Molecular weight & Molecular formula & Composition (\%) \\
\hline Eugenol & 18.25 & 164 & $\mathrm{C}_{10} \mathrm{H}_{12} \mathrm{O}_{2}$ & 85 \\
$\beta$-Caryophyllene & 19.58 & 204 & $\mathrm{C}_{15} \mathrm{H}_{24}$ & 1.5 \\
Eugenyl acetate & 21.26 & 206 & $\mathrm{C}_{12} \mathrm{H}_{14} \mathrm{O}_{3}$ & \\
\hline
\end{tabular}

TABle 2: Chemical composition of pepper (Piper nigrum) essential oil.

\begin{tabular}{lcccc}
\hline Compound $^{(1)}$ & $\mathrm{KI}^{(2)}$ & Molecular weight & Molecular formula & Composition (\%) \\
\hline$\alpha$-Thujene & 931 & 136.23 & $\mathrm{C}_{10} \mathrm{H}_{16}$ & 1.4 \\
$\alpha$-Pinene & 939 & 136.23 & $\mathrm{C}_{10} \mathrm{H}_{16}$ & 5.7 \\
Sabinene & 976 & 136.23 & $\mathrm{C}_{10} \mathrm{H}_{16}$ & 16.5 \\
B-Pinene & 980 & 136.24 & $\mathrm{C}_{10} \mathrm{H}_{16}$ & 10.7 \\
Myrcene & 991 & 136.23 & $\mathrm{C}_{10} \mathrm{H}_{16}$ & 2.0 \\
Limonene & 1031 & 136.24 & $\mathrm{C}_{10} \mathrm{H}_{16}$ & 18.8 \\
B-Phellandrene & 1053 & 136.23 & $\mathrm{C}_{10} \mathrm{H}_{16}$ & 1.8 \\
Linalool & 1098 & 154.25 & $\mathrm{C}_{10} \mathrm{H}_{18} \mathrm{O}$ & 1.1 \\
Terpinen-4-ol & 1178 & 154.25 & $\mathrm{C}_{10} \mathrm{H}_{18} \mathrm{O}$ & 1.7 \\
$\Delta$-Elemene & 1339 & $\mathrm{C}_{15} \mathrm{H}_{24}$ & 1.9 \\
Germacrene B & 1560 & 204.35 & $\mathrm{C}_{15} \mathrm{H}_{24}$ & 1.4 \\
$\beta$-Caryophyllene & 1625 & 204.35 & $\mathrm{C}_{15} \mathrm{H}_{26} \mathrm{O}$ & 15.1 \\
\hline
\end{tabular}

${ }^{1}$ Main compounds in essential oil. ${ }^{2}$ Kováts indices in reference to $n$-alkanes $\left(\mathrm{C}_{8}-\mathrm{C}_{22}\right)$.

growth similar to $A$. niger at $100 \mathrm{ppm}$ of $7.17-7.19 \mathrm{~cm}$, higher values than those obtained with the clove essential oil. Different studies have demonstrated that clove essential oil possesses in vitro antifungal activity, affecting species that often develop in food, such as Paecilomyces, Penicillium sp., Rhizopus sp., Rhizomucor sp., and even some species of Aspergillus [27]. It has also been demonstrated in vitro that clove inhibits the growth of Aspergillus flavus, A. niger, Fusarium oxysporum, F. chrysogenum, and Penicillium sp., starting at 500 and $1000 \mathrm{ppm}$ [28]. Generally, the main components in essential oils reflect their biophysical and biological characteristics [9]. However, it is reasonable to assume that the biological activity of the clove essential oil can be related to the presence of a high concentration of Eugenol (75-100\%) [29]. Components with phenolic structure such as eugenol are highly active against microorganisms [30]. This phenolic compound can denature proteins, and it reacts with phospholipids of the cell membrane that change their permeability [31], which is explained by the acid nature of the hydroxyl group, which forms a hydrogen bond with an active enzymatic core.

3.3.2. Antifungal Activity of Pepper (Piper nigrum). Pepper essential oils and functional extracts did not show a significant inhibition activity against Fusarium oxysporum and Aspergillus niger. In the case of the essential oil, it was observed a growth of $7.5 \mathrm{~cm}$ at $100 \mathrm{ppm}$ and of $7.3 \mathrm{~cm}$ at $200 \mathrm{ppm}$, confirming that it remains constant up to $500 \mathrm{ppm}$ where it is observed a reduction to $6.0 \mathrm{~cm}$. In all the pepper functional extracts, there was a very similar behavior to essential oil, since in the extracts it was observed an average growth of $7.3 \mathrm{~cm}$ at concentrations of 100,200 , and $300 \mathrm{ppm}$, while at 400 and $500 \mathrm{ppm}$, there was a reduction to $6.8 \mathrm{~cm}$ and $6.5 \mathrm{~cm}$, respectively. In the case of Aspergillus niger, the growth was not affected significantly by the pepper essential oil, which at the concentrations of 100-300 ppm remained between $7.33-7.36 \mathrm{~cm}$; however, at $400 \mathrm{ppm}$, there was a slight decrease to $6.81 \mathrm{~cm}$. In the functional extracts, it is observed a similar behavior, obtaining lower growth in the extract pepper- $\mathrm{C}_{14}$ of $7.25 \mathrm{~cm}$ and a maximum mycelial growth of $7.7 \mathrm{~cm}$ after the incubation period. Therefore, it may be concluded that pepper did not show fungistatic and fungicide activity before both fungi. However, studies have shown that pepper essential oil presents antifungal activity particularly against fungi such as Trichophyton terrestre, $T$. tonsurans, Candida albicans, Monosporium apiospermum, A. fumigatus, A. nidulans, Sporotrichum schencki, and Histoplasma capsulatum [32]; this antimicrobial activity of the essential oil is influenced by their chemical composition, constituted by a combination of monoterpenoids and sesquiterpenoids considered responsible of the activity against organisms [33]. Some authors [34, 35] mention that the primary target of antimicotic chemotherapeutic agents is the fungus membrane. Most fungi contain ergosterol as the main component of the membrane, except for some oomycetes. Thus, many antimicotic agents act either fixing ergosterol or blocking biosynthesis, inhibiting an enzyme of the group cytochromes P-450 which catalyzes one of the first steps in esterol biosynthesis in fungi and animal cells, producingdemethylation of lanosterol, biosynthetic precursor of cholesteroland ergosterol. Others antimycotic agents block squalene epoxidase and are often used as topicals.Therefore, strategies that alter or block ergosterol synthesis affect permeability of cell membrane and the activity of enzymes linked to such membrane, which leads to inhibition of growth and later to cellular death.

3.4. Evaluation of In Vivo Antifungal Activity of EOs and FEs. Based on the results obtained in the in vitro tests, it was evaluated the biological activity of essential oils and 


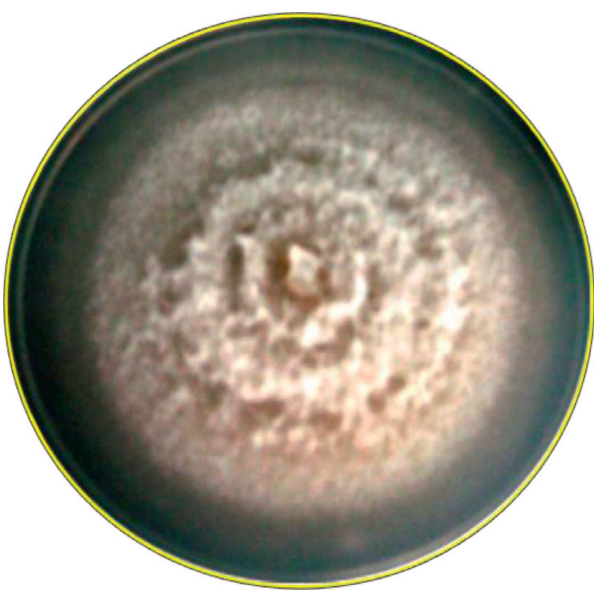

(a)

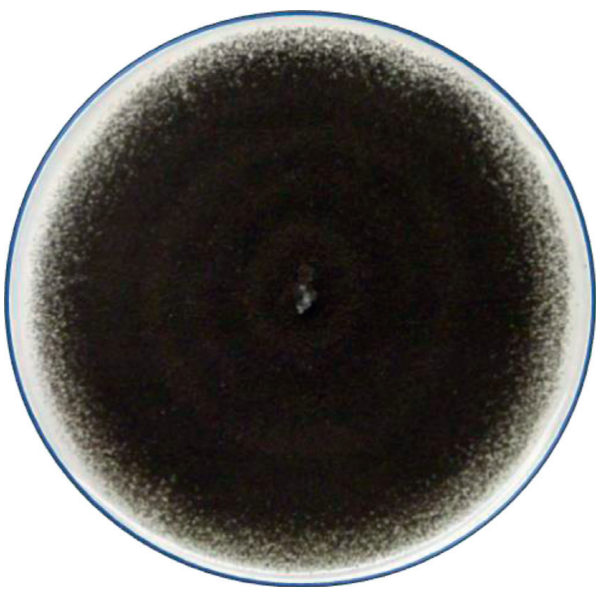

(c)

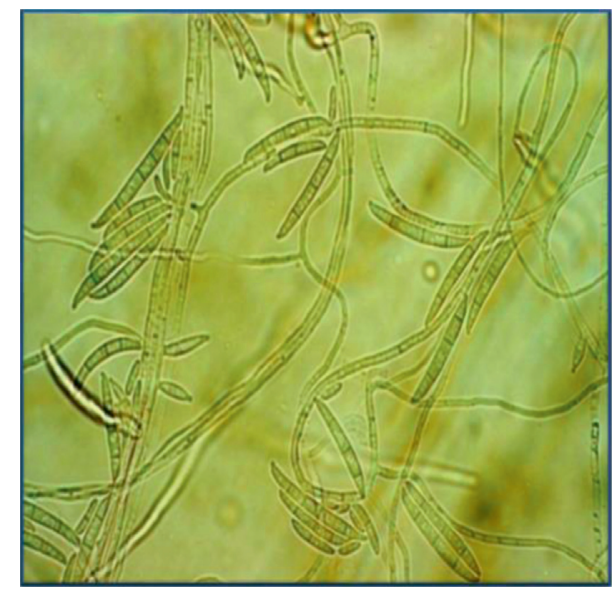

(b)

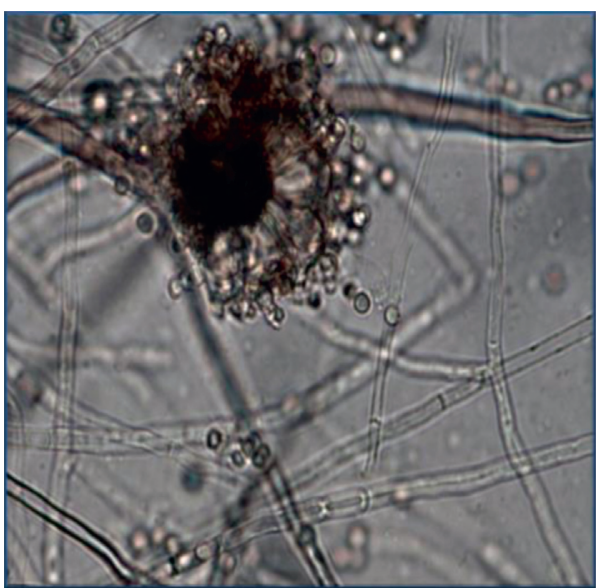

(d)

Figure 1: Colonies and microscopic morphology at 10x and 40x of Fusarium oxysporum (a, b) and Aspergillus niger (c, d) at 9 days of incubation on PDA agar.

TABLE 3: Effects of essential oils (EOs) and functional extracts (FEs) of clove and pepper in vitro at various concentrations on radial growth of Fusarium oxysporum and Aspergillus niger.

\begin{tabular}{|c|c|c|c|c|c|c|c|c|c|c|c|c|c|c|c|c|c|c|c|c|}
\hline \multirow[b]{3}{*}{ (ppm) } & \multicolumn{10}{|c|}{ Clove (Eugenia caryophyllata) } & \multicolumn{10}{|c|}{ Pepper (Piper nigrum L.) } \\
\hline & \multicolumn{5}{|c|}{ Fusarium oxysporum } & \multicolumn{5}{|c|}{ Aspergillus niger } & \multicolumn{5}{|c|}{ Fusarium oxysporum } & \multicolumn{5}{|c|}{ Aspergillus niger } \\
\hline & $\mathrm{EO}$ & $\begin{array}{l}\text { FEs- } \\
\text { C10 }\end{array}$ & $\begin{array}{l}\text { FEs- } \\
\text { C11 }\end{array}$ & $\begin{array}{l}\text { FEs- } \\
\text { C12 }\end{array}$ & $\begin{array}{l}\text { FEs- } \\
\text { C14 }\end{array}$ & $\mathrm{EO}$ & $\begin{array}{l}\text { FEs- } \\
\text { C10 }\end{array}$ & $\begin{array}{l}\text { FEs- } \\
\text { C11 }\end{array}$ & $\begin{array}{l}\text { FEs- } \\
\text { C12 }\end{array}$ & $\begin{array}{l}\text { FEs- } \\
\text { C14 }\end{array}$ & $\mathrm{EO}$ & $\begin{array}{l}\text { FEs- } \\
\text { C10 }\end{array}$ & $\begin{array}{l}\text { FEs- } \\
\text { C11 }\end{array}$ & $\begin{array}{l}\text { FEs- } \\
\text { C12 }\end{array}$ & $\begin{array}{l}\text { FEs- } \\
\text { C14 }\end{array}$ & EO & $\begin{array}{l}\text { FEs- } \\
\text { C10 }\end{array}$ & $\begin{array}{l}\text { FEs- } \\
\text { C11 }\end{array}$ & $\begin{array}{l}\text { FEs- } \\
\text { C12 }\end{array}$ & $\begin{array}{l}\text { FEs- } \\
\text { C14 }\end{array}$ \\
\hline 0 & 7.72 & 7.72 & 7.72 & 7.72 & 7.72 & 7.23 & 7.23 & 7.23 & 7.23 & 7.23 & 7.72 & 7.72 & 7.72 & 7.72 & 7.72 & 7.23 & 7.23 & 7.23 & 7.23 & 7.23 \\
\hline 100 & 5.69 & 6.53 & 6.61 & 4.76 & 6.33 & 6.12 & 6.23 & 7.19 & 6.38 & 7.16 & 7.53 & 7.33 & 7.65 & 7.41 & 7.56 & 7.36 & 7.64 & 7.48 & 7.73 & 7.79 \\
\hline 200 & 3.32 & 4.28 & 4.36 & 4.39 & 4.08 & 1.98 & 2.5 & 2.72 & 2.78 & 4.35 & 7.33 & 7.45 & 7.5 & 7.38 & 7.61 & 7.34 & 7.7 & 7.48 & 7.73 & 7.69 \\
\hline 300 & 2.41 & 2.65 & 2.66 & 2.65 & 2.67 & 0.83 & 1.26 & 1.05 & 1.58 & 1.71 & 6.97 & 7.28 & 7.35 & 6.96 & 7.28 & 7.33 & 7.58 & 7.4 & 7.6 & 7.58 \\
\hline 400 & 1.8 & 1.28 & 1.33 & 1.19 & 1.14 & 0 & 0.58 & 0.68 & 0.35 & 0.53 & 6.32 & 6.8 & 6.7 & 6.62 & 7.21 & 6.81 & 7.53 & 7.4 & 7.33 & 7.43 \\
\hline 500 & 0 & 0.7 & 0.65 & 0.69 & 0.26 & 0 & 0 & 0 & 0 & 0 & 6.03 & 6.54 & 6.35 & 6.41 & 6.61 & 6.78 & 7.38 & 7.41 & 7.49 & 7.25 \\
\hline
\end{tabular}

functional extracts against $F$. oxysporum and $A$. niger with in vivo methods. The damage in the tomato fruit was analyzed. In the evaluation, the extracts with the higher inhibitory activity were used, that is, the clove essential oil and functional extracts: clove- $\mathrm{C}_{10}$, clove- $\mathrm{C}_{11}$, clove- $\mathrm{C}_{12}$, and clove- $\mathrm{C}_{14}$, at concentrations of $350 \mathrm{ppm}, 400 \mathrm{ppm}$, and $450 \mathrm{ppm}$. The results obtained are shown in Table 4 , where it can be observed that on the tomato surface there is a circular area, white at the beginning, evolving to a darker color. The lesions are observed covered with a cottony cluster of white mycelium, which causes softening and destruction of vegetable tissue; no exudate is produced, but dehydration and destruction of tissue occurs. As it can be observed, it was not possible to determine whether the clove essential oil and some functional extracts were capable of inhibiting the growth of $F$. oxysporum, except for the extract clove- $\mathrm{C}_{10}$ where it could be observed a significant variation in each treatment. Soft rot generated 
TABLE 4: In vivo antifungal activity of clove essential oil and functional extracts at Solanum lycopersicum L var "bola".

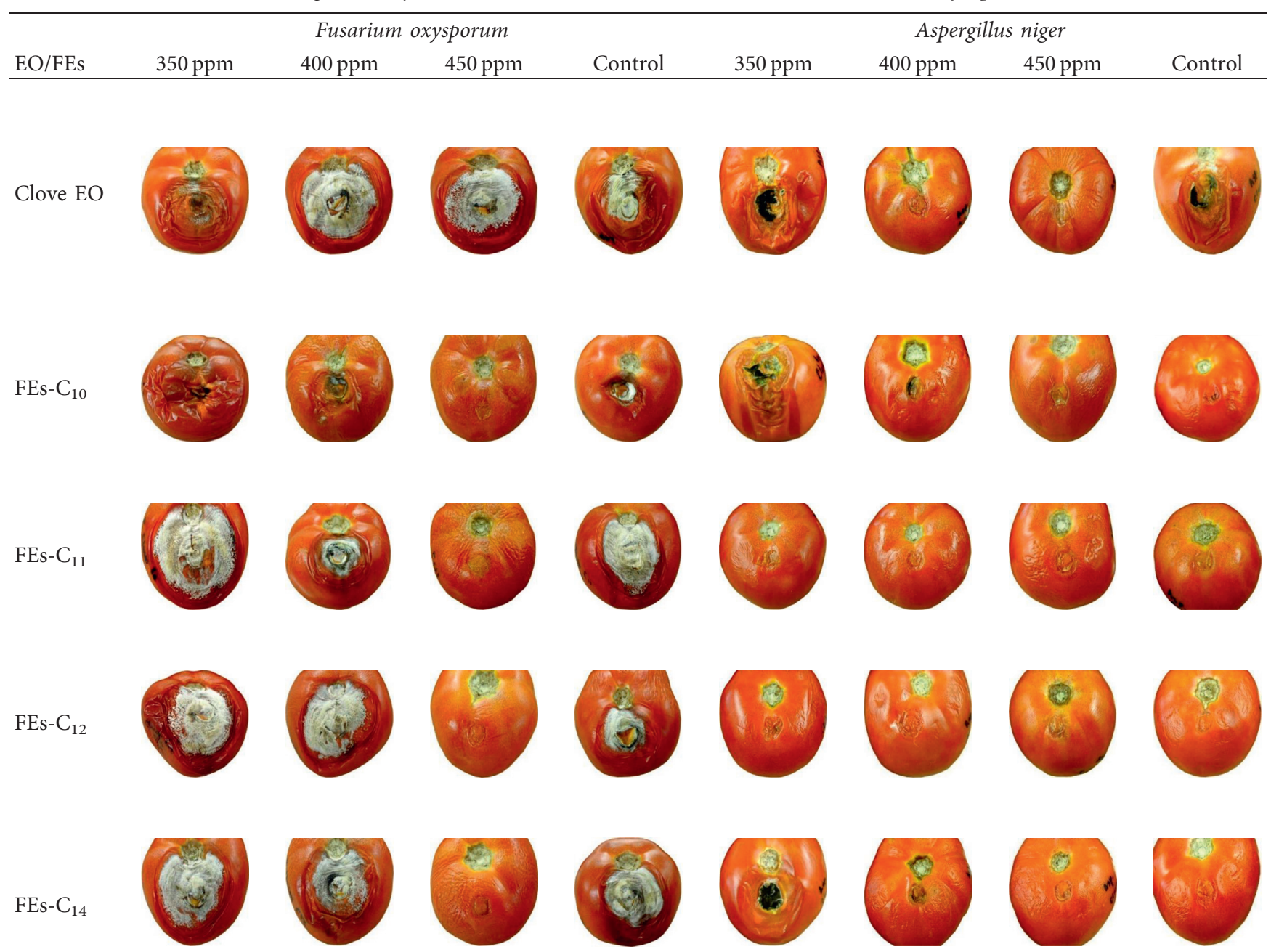

by $A$. niger could also be observed in the treatments where no inhibition was determined, with the presence of a fungal mass; in addition to this, no fungal development was present in the fruit surface, causing necrosis of the tissue that develops from the inoculation site to the internal region. Therefore, we can confirm that the essential oils and functional extracts evaluated in vivo against the species $A$. niger and $F$. oxysporum in the tomato fruit did not show strong inhibition; however, total inhibition could be demonstrated in the in vitro tests; this can be attributed to the existence of some factors that may affect the antifungal efficiency, such as the food components, inactivation due to the addition of other component, effects of $\mathrm{pH}$ over antifungal stability and activity, unequal distribution in the food matrix, and low solubility of extracts [36]. Additionally, AguilarGonzalez et al. [37] demonstrated in vitro the effectiveness of mustard EO vapor against $A$. niger in tomatoes and concluded that mustard EO contains highly volatile compounds with strong inhibitory effects. However, these results were obtained with essential oils used in the vapor phase.

\section{Conclusions}

In conclusion, clove (Eugenia caryophyllata) and pepper (Piper nigrum L.) essentials oils and functional extracts could provide an alternative solution to the use of hazardous chemical fungicides for the treatment of tomato fruit during storage and transportation to reduce postharvest infection. In view of the economic importance of tomato, the possibility of using products with a lower risk to human health and the environment than synthetic pesticides in controlling Fusarium oxysporum and Aspergillus niger wilt is very promising.

\section{Data Availability}

The data used to support the findings of this study are included within the article.

\section{Conflicts of Interest}

The authors declare that they have no conflicts of interest regarding the publication of this article. 


\section{Acknowledgments}

The authors thank the Facultad de Ciencias Quimicas at the Universidad Autonoma de Chihuahua for the economic support to conduct this study.

\section{References}

[1] D. Jasso De Rodriguez, N. A. Gaytan Sanchez, R. Rodriguez Garcia et al., "Antifungal activity of Junglans spp. and Carya ssp. Ethanol extracts against Fusarium oxysporum on tomato under greenhouse conditions," Industrial Crops and Products, vol. 138, p. 111442, 2019.

[2] C. Gómez-Ramírez, M. E. Sosa-Morales, E. Palou, and A. López-Malo, "Aspergillus niger time to growth in dried tomatoes," International Journal of Food Microbiology, vol. 164, no. 1, pp. 23-25, 2013.

[3] L. Burketova, L. Trda, P. G. Ott, and O. Valentova, "Bio-based resistance inducers for sustainable plant protection against pathogens," Biotechnology Advances, vol. 33, no. 6, pp. 9941004, 2015.

[4] M. Sathiyabama and R. E. Charles, "Fungal cell wall polymer based nanoparticles in protection of tomato plants from wilt disease caused by Fusarium oxysporum f.sp. lycopersici," Carbohydrate Polymers, vol. 133, pp. 400-407, 2015.

[5] A. Sharma, N. K. Sharma, A. Srivastava et al., "Clove and lemongrass oil based non-ionic nanoemulsion for suppressing the growth of plant pathogenic Fusarium oxysporum f.sp. lycopersici," Industrial Crops and Products, vol. 123, pp. 353-362, 2018.

[6] R. J. McGover, "Magnagement of tomato diseases caused by Fusarium oxysporum," Crop Protection, vol. 73, pp. 78-92, 2015.

[7] J. A. Ukeh and N. V. Chiejina, "Preliminary investigations of the cause of post-harvest fungal rot of tomato," Journal of Pharmacy and Biological Sciences, vol. 4, no. 5, pp. 36-39, 2012.

[8] A. S. Derbalah, M. S. El-Mahrouk, and A. B. El-Sayed, "Efficacy and safety of some plant extracts against tomato early blight disease caused by Alternaria solani," Plant Pathology Journal, vol. 10, no. 3, pp. 115-121, 2011.

[9] E. Zorzi-Tamazoni, G. Schiavo-Griggio, E. Pessin-Broilo, R. Teresinha da silva Ribeiro, G. L. Goncalvez-Soares, and J. Schwambach, "Screening for inhibitory activity of essential oils on fungal tomato pathogen Stemphylium solani Weber," Biocatalysis and Agricultural Biotechnology, vol. 16, pp. 364$372,2018$.

[10] F. Bakkali, S. Averbeck, D. Averbeck, and M. Idaomar, "Biological effects of essential oils-a review," Food and Chemical Toxicology, vol. 46, no. 2, pp. 446-475, 2008.

[11] S. S. Mahmoud and R. B. Croteau, "Strategies for transgenic manipulation of monoterpene biosynthesis in plants," Trends in Plant Science, vol. 7, no. 8, pp. 366-373, 2002.

[12] S. Burt, "Essential oils: their antibacterial properties and potential applications in foods-a review," International Journal of Food Microbiology, vol. 94, no. 3, pp. 223-253, 2004.

[13] M. Hyldgaard, T. Mygind, and R. L. Meyer, "Essential oils in food preservation: mode of action, synergies, and interactions with food matrix components," Frontiers in Microbiology, vol. 3, pp. 1-24, 2012.

[14] I. C. De Jesus, G. G. Santos Frazão, A. F. Blank, and L. C. L. De Aquino Santana, "Myrcia ovata cambessedes essential oils: a proposal for a novel natural antimicrobial against foodborne bacteria," Microbial Pathogenesis, vol. 99, pp. 142-147, 2016.

[15] G. A. Helal, M. M. Sarhan, A. N. K. Abu Shahla, and E. K. Abou El-Khair, "Effects of Cymbopogon citratus L. essential oil on the growth, lipid content and morphogenesis of Aspergillus niger ML2-strain," Journal of Basic Microbiology, vol. 46, no. 6, pp. 456-469, 2006.

[16] K. Rammanee and T. Hongpattarakere, "Effects of tropical citrus essential oils on growth, aflatoxin production, and ultrastructure alterations of Aspergillus flavus and Aspergillus parasiticus," Food and Bioprocess Technology, vol. 4, no. 6, pp. 1050-1059, 2011.

[17] A. K. Dwivedy, M. Kumar, N. Upadhyay, B. Prakash, and N. K. Dubey, "Plant essential oils against food borne fungi and mycotoxins," Current Opinion in Food Science, vol. 11, pp. 16-21, 2016.

[18] J. Tian, B. Huang, X. Luo et al., "The control of Aspergillus flavus with Cinnamomum jensenianum Hand.-Mazz essential oil and its potential use as a food preservative," Food Chemistry, vol. 130, no. 3, pp. 520-527, 2012.

[19] B. Prakash, P. K. Mishra, A. Kedia, and N. K. Dubey, “Antifungal, antiaflatoxin and antioxidant potential of chemically characterized Boswellia carterii Birdw essential oil and its in vivo practical applicability in preservation of Piper nigrum $\mathrm{L}$. fruits," LWT-Food Science and Technology, vol. 56, no. 2, pp. 240-247, 2014.

[20] P. Reyes-Chaparro, N. Gutierrez-Mendez, E. Salas-Muñoz, J. G. Ayala-Soto, D. Chavez-Flores, and L. Hernández-Ochoa, "Effect of the addition of essential oils and functional extracts of clove on physicochemical properties of chitosan-based films," International Journal of Polymer Science, vol. 2015, pp. 1-6, 2015.

[21] L. Hernández-Ochoa, C. A. Macías-Castañeda, G. V. NevárezMoorillón, E. Salas-Muñoz, and F. Sandoval-Salas, "Antimicrobial activity of chitosan-based films including spices' essential oils and functional extracts," CyTA-Journal of Food, vol. 10, no. 2, pp. 85-91, 2012.

[22] L. Jirovetz, G. Buchbauer, I. Stoilova, A. Stoyanova, A. Krastanov, and E. Schmidt, "Chemical composition and antioxidant properties of clove leaf essential oil," Journal of Agricultural and Food Chemistry, vol. 54, no. 17, pp. 63036307, 2006

[23] G. Fichi, G. Flamini, F. Giovanelli, D. Otranto, and S. Perrucci, "Efficacy of an essential oil of Eugenia caryophyllata against Psoroptes cuniculi," Experimental Parasitology, vol. 115, no. 2, pp. 168-172, 2007.

[24] M. A. Abdulazeez, I. Sani, D. J. Bolanle, and S. A. Abdulmalik, Essential Oils in Food Preservation, Flavor and Safety: Black Pepper (Piper nigrum L.) Oil, V. R. Preedy, Ed., vol. 31, pp. 277-285, Academic Press Elsevier, Cambridge, MA, USA, 2016.

[25] A. Shanin, N. Shamsun, M. D. Abukawsar, and K. S. Sudhungshu, "Comparative studies on physical properties and GC-MS analysis of essential oils of the two varieties of the black pepper (Piper nigrum L.)," International Journal of Pharmaceutical and Phytopharmacological Research, vol. 2, no. 2, pp. 67-70, 2012.

[26] K. Purushothaman, S. K. Bhat, S. A. Singh, G. K. Marathe, and A. R. G. Appu Rao, "Aspartic protease from Aspergillus niger: molecular characterization and interaction with pepstatin A," International Journal of Biological Macromolecules, vol. 139, pp. 199-212, 2019.

[27] T. Benoit, A. Nelly Contet, M. Machourt, and A. Debourgogne, "Molecular identification of Fusarium 
species complexes: which gene and which database to choose in clinical practice," Journal de Mycologie Medicale, vol. 29, pp. 56-58, 2019.

[28] Q. Kritzinger, T. Aveling, and W. Marasas, "Effect of essential plant oils on storage fungi germination and emergence of cowpea seeds," Journal of Seed Science and Technology, vol. 30, no. 3, pp. 609-619, 2002.

[29] E. Pinto, L. Vale-Silva, C. Cavaleiro, and L. Salgueiro, "Antifungal activity of the clove essential oil from Syzygium aromaticum on Candida, Aspergillus and dermatophyte species," Journal of Medical Microbiology, vol. 58, no. 11, pp. 1454-1462, 2009.

[30] C. Gupta, A. Garg, R. Uniyal, and S. Gupta, "Comparison of antimicrobial activities of clove oil and its extract on some food borne microbes," The Internet Journal of Microbiology, vol. 7, pp. 1-7, 2008.

[31] N. Bhuiyan, J. Begum, N. Nandi, and F. Akter, "Constituents of the essential oil from leaves and buds of clove (Syzigium caryophyllatum)," African Journal of Plant Science, vol. 4, no. 11 , pp. $451-454,2010$.

[32] M. Sayeed Akthar, G. Birhanu, and S. Demisse, "Antimicrobial activity of Piper nigrum L. and Cassia didymobotyra L. leaf extract on selected food borne pathogens," Asian Pacific Journal of Tropical Disease, vol. 4, no. 2, pp. 911-919, 2014.

[33] I. Sasidharan and A. Nirmala, "Comparative chemical composition and antimicrobial activity of berry and leaf essential oils of Piper nigrum L." International Journal of Biological and Medical Research, vol. 1, no. 4, pp. 215-218, 2010.

[34] R. Zulueta-Rodríguez, D. Trejo-Aguilar, and A. Trigos-Landa, Maravillosos Mundo de Los Hongos, pp. 91-102, Editorial Universidad Veracruzana, Xalapa Veracruz, México, 2007.

[35] Á. Trigos and A. Ortega-Regules, "Selective destruction of microscopic fungi through photo-oxidation of ergosterol," Mycologia, vol. 94, no. 4, pp. 563-568, 2002.

[36] S. Alzamora, M. S. Tapia, and A. López-Malo, Minimaly Processed Fruit and Vegetables: Fundamental Aspect and Applications, pp. 243-251, Editorial Aspen Publishers, Gaithesburg, MD, USA, 2000.

[37] A. E. Aguilar-González, E. Palou, and A. López-Malo, "Response of Aspergillus niger inoculated on tomatoes exposed to vapor phase mustard essential oil for short or long periods and sensory evaluation of treated tomatoes," Journal of Food Quality, vol. 2017, pp. 1-7, 2017. 